\section{Summary points}

Strengthened and performing health systems remain critical to achieving health related millennium development goals in Africa

This will require increased integration and investment in various components of the "back office" by both national governments and their development partners

The lessons and experiences relevant to policy and programming need to be harnessed and shared

availability of considerable international funding for HIV treatment, substantial resources should be directed to strengthening the back office.

Contributors and sources: LD is a community physician and epidemiologist who has worked on health systems development and strengthening in Africa for over 15 years, with experience in the design of community managed primary care programmes that harness both public and private healthcare resources to improve service delivery. She is also the executive secretary of a pan-African partnership, the African Council for Sustainable Health Development (ACOSHED). AR is a medical anthropologist with more than 20 years of field experience in the design and implementation of health system programmes and the underlying private-public partnerships. She has also worked for the Action Program on Essential Drugs at WHO, as programme officer at the United Nations Economic and Social Council for Asia and Pacific, and at UNAIDS in Geneva.

Competing interests: None declared.

1 United Nations Development Program. Millennium Development Goals in Human Development Program. New York: UNDP, 2003.
2 World Health Organization. Health in the millennium development goals. Geneva: WHO, 2005. www.who.int/mdg/publications/mdg_report/en/ (accessed 15 Sep 2005)

3 Dare O. Expanding the frontiers of partnership for health systems strengthening in Africa. 32nd Conference of the Global Health Council, Washington, DC, 31 May-3 June 2005. www.globalhealth.org/ conference2005

4 Marie-Helene B, Clary H. Scaling up prevention of mother-to-child transmission of HIV in developing countries: results from the PMTCT donation programs. Tanzania National AIDS conference, Tanzania, 13-16 donation programs

December 2004.
Settala R, Wistar T, Muyingo S, Dintruff R, Saba J. Scaling up care and HAART programs in developing countries: access to HIV care program (AHCP) experience. International AIDS Conference Bangkok, 11-16 July 2004.

6 Buse K. Keeping a tight grip on the reins: donor control over aid coordination and management in Bangladesh. Health Policy Plan 1999;14:21928.

7 Heller P. Is there room for additional spending in the social sectors: the case of Malawi, Tanzania and Zambia? Consultation on Human Resources for Health, Oslo, 24-25 Feb 2005. www.norad.no/default.asp?V_ITEM $\mathrm{ID}=3070$ (accessed 20 Sep 2005).

8 Gottret P, Schieber G. Fiscal sustainability and predictability. Consultation on Human Resources for Health, Oslo, 24-25 Feb 2005.

9 World Health Organization. Health systems: improving performance. Geneva: WHO, 2000.

10 Saltman RB, Ferroussier-Davis O. The concept of stewardship in health policy. Bull World Health Org 2000;78:732-9.

11 Mayhew SH. Donor dealings: the impact of international donor aid on sexual and reproductive health services. Int Fam Plan Persp 2002;28: $220-4$

12 Overseas Development Institute. Aid to Africa and the UK's "2005 agenda": perspectives of European donors and implications for Japan. 2005. www.odi.org.uk/rapid/Projects/RAP0011/docs/workshop summary www.odi.

final.pdf

13 Butler D. US aid agency grilled over malaria funds. Nature 2005;435:257. 4 Levine R. Millions Saved:Proven successes in global health. Washington, DC: Center for Global Development, 2004.

15 Halstead S, Walsh JA, Wareen KS. Good health at low cost. New York: Rockefeller Foundation, 1985.

16 World Health Organization. World health report 2005. Make every mother and child count. Geneva: WHO, 2005. www.who.int/whr/2005/en/ (accessed 15 Sep 2005)

17 Cockshott WP. Diagnostic radiology: geography of a high technology. Am J Roentgenol 1979;132:339-44.

18 Ondo State Ministry of Health. Ondo State Health Plan. Akure: Ministry of Health, 2004.

19 Dare OO, Akinbobola R, Ojo KO. Utilization of research to policy: country experiences. Forum 7, Global Forum for Health Research, Geneva, 2-5 December 2003.
Centre for Health Policy University of Witwatersrand, PO Box 1038 ,

Johannesburg 2000

South Africa

Lucy Gilson

associate professor

Health Economics

Unit, School of

Public Health and

Family Medicine,

University of Cape

Town, Observatory,

7925, South Africa

Di McIntyre

associate professor

Correspondence to:

L Gilson

Lucy.gilson@

nhls.ac.za

BMJ 2005;331:762-5

\title{
Removing user fees for primary care in Africa: the need for careful action
}

\section{Lucy Gilson, Di McIntyre}

Current calls for the removal of user fees respond to evidence of their regressive impacts and their role in enhancing social exclusion-but removal must be carefully managed because this action may have negative impacts on the wider health system

User fees are once again a topic of hot policy debate in Africa. They were introduced relatively recently in many countries (box 1), but the current call is for their removal, particularly at primary care level. ${ }^{2}$ As analysts who have consistently argued against user fees, we broadly support this call. However, we recognise that this action cannot be introduced overnight and, if weakly implemented, may exacerbate the problems facing African health systems. We outline both why we believe African countries should move away from user fees, and what actions should accompany their removal to ensure that this policy change strengthens rather than undermines healthcare provision. Our suggestions are based on the experience of countries such as South Africa and Uganda that have already removed some or all fees, as well as wider experience of policy change.

\section{Why should fees be removed?}

User fees are the most regressive form of healthcare financing available; they contribute to the unaffordable cost burdens imposed on poor households; and they represent one facet of the social exclusion experienced by these households.

Out of pocket payments (which include user fees at public sector facilities) are more regressive than any other method of financing health care, capturing a higher proportion of income among poor households than wealthier ones. ${ }^{3}$ Thus, simply on the basis of the 
equity principle that those with the greatest ability to pay should make appropriately larger contributions, out of pocket payments are the least desirable way of financing health services.

At primary care level, fees are relatively low. None the less, such fees can encourage inappropriate self treatment and use of partial drug doses or may act as a barrier to early use, or perhaps any use, of health facilities. ${ }^{4}$ Increased morbidity and mortality may result. ${ }^{5} \mathrm{By}$ increasing the costs associated with illness, even a small level of fee can contribute to the impoverishment of vulnerable households. They may need to sell key assets, cut down on other necessary expenditures, or borrow, often at exorbitant interest rates, to pay for health care and cope with the loss of income resulting from illness. ${ }^{6}$ In addition, fees add to the other immense barriers, such as distance and abusive treatment by healthcare providers, that poor people face when seeking health care. Experience of these barriers is part of the lived experience of poverty in many African societies, contributing to the expectation of social exclusion among poorer groups. ${ }^{7}$

Though important, removing fees is not a simple exercise. Without supportive actions, fee removal can itself add to the performance problems of health systems.

\section{Mobilising and allocating resources}

Before fees can be removed, the levels of funding available for health care must be increased. As user fees restrict utilisation of health services and create a large pool of unmet need, fee removal is likely to result in substantial and sustained increases in utilisation. Without increased funding for health care, these increases could well lead to falling quality of care generated by drug shortages and staff difficulties in managing increased workloads. ${ }^{9}$ Where can more resources be found?

Improved tax funding for health care is a high priority and feasible option given that, in the Abuja declaration of 2001, African governments committed themselves to allocating at least $15 \%$ of government budgets to the public health sector. However, the World Health Organization's national health accounts database shows that, after the contribution of donor funds to healthcare funding is excluded, no sub-Saharan African country has yet achieved this level..$^{10}$ Cancelling African countries' debt would, by relieving government budgets from the burden of debt servicing, support increases in tax revenues allocated to health services. The G8 debt cancellation initiative is a step in the right direction, but more action on debt is required to support sustained increases in public health budgets. Donor funding might also support fee removal, but its unreliability prompts caution about its role. Instead, urgent action is needed to identify other sources of domestic healthcare financing that are sustainable and provide equitable financial protection for people needing health services.

A second action that will support fee removal is to allocate government and donor funds equitably (that is, according to need) within countries. ${ }^{11}{ }^{12}$ The areas that will require the greatest injection of additional funds are those with the highest poverty levels. These areas usually have a history of underfunding, but as

\section{Box 1: Operation of user fees in African countries ${ }^{1}$}

Users of public sector health services in most African countries are required to pay fees at the point of service delivery. Some African countries have a relatively long tradition of charging user fees, but most introduced fees in the late 1980 s and early 1990 s, partly in response to pressure from international organisations such as the World Bank and International

Monetary Fund.

Generally, at least some form of fee is paid before care is received, particularly for outpatient services. The fee may be either an all inclusive flat rate or a fee for each service received (consultations, diagnostic tests, medicines dispensed, etc).

Services that are important for public health (such as treatment of communicable diseases, immunisation of children, family planning, antenatal care) are often exempt from fees. However, mechanisms for protecting the poor from the financial barrier to health service access imposed by fees have generally proved ineffective. In many countries, revenue from user fees is partially or fully retained at the facility level and used to support service delivery (purchase of additional pharmaceutical supplies or improved cleanliness of the facility, for example). Often the local community or area managers have some discretion over the use of these funds.

they have the greatest levels of unmet need associated with financial access barriers, they are likely to experience the greatest utilisation increases after fee removal.

Finally, developments in healthcare financing need to be underpinned by changes in the terms of trade faced by African countries, such as market barriers to trade in food products, as these generate huge resource outflows. ${ }^{11}$

\section{Effective implementation strategies}

Experience across a range of health system reforms indicates that the process of policy change (representing the interaction between actors, processes, design features, and context) has a critical influence over the impact of such change (box 2). ${ }^{13} 14$ Thus it is important to pay careful attention to the processes and strategies through which any policy change is implemented (box 3).

Leadership is necessary to sustain support for policy change. Leaders must establish and then promote a vision for policy change, ${ }^{15}$ and they must

Box 2: Experience of financing reform in South Africa (1994-9) and Zambia (1991-9) $)^{14}$

- Political pressure generated demands for speedy policy change, limiting the preparation and planning for implementation across policies

- The personal influence of ministers of health over decisions frequently determined which policies were implemented, which were not, and which remained under discussion

- The relative lack of power of technical analysts, and weak relationships between senior government officials and non-government analysts, also helps to explain differences in implementation

- Opposition from key actors, such as ministers of health, to particular design features helps explain the slow implementation, or lack of implementation, of some policies

- The failure of policy developers to provide information about new policies to those responsible for implementation and to the intended beneficiaries of the policies, and failure to ensure policies were accepted, influenced the limited and unexpected impacts of policies

- The failure to build implementation capacity, including adequate policy monitoring systems, also helped to explain limited and unexpected policy impacts 
coordinate the many different groups, within and outside of government, involved in policy implementation. ${ }^{16}$ Allocating this responsibility to a specific unit establishes a group to champion the policy as well as ensuring a focus of accountability for implementation (strategy 1, box 3).

To avoid negative impacts on morale and performance, the responses of health workers and managers must be actively managed. As frontline health workers and managers provide the point at which patients meet the health system, their behaviour influences patients' experience of health care and how policies are implemented. In South Africa, the removal of fees led to increased healthcare utilisation, but health workers felt they were not adequately informed and were thus unprepared for these increases (box 2). ${ }^{8}$ Unnecessary tensions at primary care level resulted: patients complained that health workers treated them badly and providers complained that patients abused the services. ${ }^{17-19}$ Similar adverse impacts on staff morale were reported in Uganda, related to increases of around $47 \%$ in average workload and the loss of the fee revenue that had been used to supplement staff salaries. ${ }^{20}$

A key strategy in managing staff responses is to develop active communication strategies that inform (newsletters, for example) and provide opportunities for dialogue (meetings, for example) between senior health managers and local level health workers (strategy 2). Through active engagement with implementers, such dialogue can elicit good ideas about how to implement the policy effectively as well as enhance the acceptability of the new policy and maintain morale..$^{15}$ In addition, where uses for revenue had been decided at local level and revenue had been, in part, allocated to supplement salaries, new strategies to decentralise authority and boost salaries will be required. One option is to establish locally controlled operational funds for activities that support fee removal (strategy 3).

To encourage utilisation and counter improper implementation practices (such as heath workers continuing to charge fees), it is important to ensure that

\section{Box 3: Practical strategies for managing fee removal}

1. Give a specific government unit the task of coordinating fee removal and the other actions necessary to strengthen the health system

2. Communicate clearly with health workers and managers about the policy vision and goals, as well as about what and when actions will be taken-through meetings, supervision visits, newsletters, etc

3. Establish new funds at local level, controlled by managers, to allow the managers to make small-scale spending decisions

4. Before the policy change, start a wide ranging public information campaign including radio spots, newspaper articles, posters, meetings with village leaders to communicate the policy vision and goals to the general public and to communicate the details of what users can expect to experience at facilities

5. Plan for adequate drugs and staff to be available to cope with increased utilisation, and plan how to tackle wider drug and staffing problems in the longer term

6. Improve physical access to health services, particularly through "close to client" services

7. Establish monitoring systems that cover utilisation trends, including the relative use of preventive versus curative care, and give health workers and managers opportunities to feed back on health facility experiences the general public knows about fee removal (strategy 4). Another critical step, with impact on health workers' and the public's experience and perceptions of this policy change, is to plan adequately for implementation (strategy 5). In South Africa, most health workers and managers initially heard about the first stage of fee removal when the country's president announced it in a public address on 24 May 1994, just days before its introduction on 1 June. ${ }^{17}$ They were not able to plan for implementation, and drug supplies were quickly exhausted as utilisation increased, frustrating health workers and patients. ${ }^{9}$ In contrast, in the recent removal of user fees in Uganda, more extensive planning was undertaken and improved supplies have supported increased utilisation. For example, the Ugandan ministry of health provided a $\$ 5.5 \mathrm{~m}$ (£3m; $€ 4.5 \mathrm{~m}$ ) buffer fund to offset the potential impact on availability of drugs arising from the loss of revenue and increases in utilisation. ${ }^{20}$ In any setting the longer term planning required to sustain fee removal includes wider action to expand the production, promote the retention, and enhance the productivity of the public health workforce. ${ }^{21}$

Transport to health facilities is often a major cost for households. Strategies to improve close-to-client health services will be needed to address the problem of access and the burden of illness costs on poor households (strategy 6). These strategies include building additional clinics, increasing community based health worker programmes, and home based treatment of key illnesses such as malaria. Such actions are also important in reducing levels of inappropriate self treatment.

Monitoring systems (strategy 7) should generate relevant, routine information as well as providing opportunities to share health workers' and managers' experiences. ${ }^{14}{ }^{15}$ Learning from such experience is vital in enabling the health system to strengthen the next steps of policy change.

\section{Conclusion}

Because of the diverse implementation needs, removing user fees is not a simple "stroke of the pen" exercise. We urge international donors and agencies to support African governments in planning for fee removal and in linking this single action to broader improvements within health systems. We also call for sensitivity in how international donors and agencies approach African countries on the issue of fee removal. Governments that have introduced user fees relatively recently, often in response to donors' requirements, are now looking sceptically at the call to remove them. Fee removal must be underpinned by action at the international level that allows for the sustained mobilisation of resources to achieve human rights to health, along with health equity goals.

LG holds a joint appointment between the University of Witwatersrand, South Africa, and the London School of Hygiene and Tropical Medicine, UK.

Contributors and sources: LG and DMcI are health economists and health policy analysts based in South Africa who have conducted work on user fees in Africa over the past 20 years, including empirical studies, literature reviews, and conceptual work. The piece draws on this joint body of work, and on the authors' current engagements around user fees within African health policy networks (particularly the Regional Network for Equity in 


\section{Summary points}

Removing user fees for primary care is important in offering financial protection to poor African households

Fee removal must be accompanied by increased national budgets for health care to protect the quality of health care in the face of increased utilisation

Careful and deliberate implementation strategies are needed to ensure that fee removal achieves its objectives

National action must be supported by international action that is sensitive to national circumstances and underpins the sustained mobilisation of resources

Health in Southern Africa, EQUINET, and HEPNet, the Health Economics and Policy Network in Africa). It responds to current calls, such as those of the Africa Commission, for the removal of primary care user fees in Africa. An earlier, substantively different, version of this piece was prepared by the authors as an editorial for the electronic newsletter of EQUINET.

Competing interests: None declared.

Gilson L. The lessons of user fee experience in Africa. Health Policy Pla 1997; 12:273-85.

2 Commission for Africa. Our common interest: report of the Commission for Africa. London: Commission for Africa, 2005. www. commissionforafrica.org/english/report/thereport/english/11-03-05 cr report.pdf (accessed 19 May 2005).

Van Doorslaer $\mathrm{E}$, Wagstaff A. Equity in the finance of health care: meth ods and findings. In: Van Doorslaer E, Wagstaff A, Rutten F, eds. Equity in the finance and delivery of health care: An international perspective. New York: Oxford University Press, 1993.

4 Russell S. The economic burden of illness for households in developing countries: a review of studies focusing on malaria, tuberculosis and human immunodeficiency virus/acquired immunodeficiency syndrome. Am J Trop Med Hyg 2004;7(suppl 2):147-55.

5 James C, Morris SS, Keith R, Taylor A. Impact on child mortality of removing user fees: simulation model. BMJ 2005;331:747-9.

6 McIntyre D, Thiede M, Dahlgren G, Whitehead M. What are the economic consequences for households of illness and of paying for health care in low- and middle-income country contexts? Soc Sci Med (in press).

7 Tibandebage P, Mackintosh M. The market shaping of charges, trust and Thuse:

Deininger K, Mpuga P. Economic and welfare effects of the abolition of health user fees: evidence from Uganda. Washington, DC: World Bank, 2004. (World Bank policy research working paper 3276.)

McCoy D. Free health care for pregnant women and children under six in South Africa: an impact assessment. Durban: Health Systems Trust, 1996.

10 World Health Organization. World health report-NHA annexes. www. who.int/nha/country/whrannex/en (accessed 14 Sep 2005).

11 EQUINET Steering Committee (Regional Network for Equinet in Health in Southern Africa). Reclaiming the state: achieving people's health, challenging injustice. Harare: EQUINET, 2004. (EQUINET policy series No 15.)

12 McIntyre D, Muirhead D, Gilson L. Geographic patterns of deprivation and health inequities in South Africa: informing health equity analyses and health inequities in South Africa: informing health equity analyses
and public resource allocation strategies. Health Policy Plan 2002;17(suppl and public resource allocation strategies. Health Policy Plan 2002;17 (supp 1):30-9.

13 Gilson L, Mills A. Health sector reform in sub-Saharan Africa: lessons of the last ten years. Health Policy 1995;32:215-43.

14 Gilson L, Doherty J, Lake S, McIntyre D, Mwikisa C, Thomas S. The SAZA study: implementing financing reform in South Africa and Zambia. Health Policy Plan 2003;18:31-46.

15 Osborne SP, Brown K. Managing change and innovation in public service organizations. London: Routledge, 2005.

16 Gilson L, Travis P. Health system decentralization in Africa: an overview of experiences in eight countries. Geneva: World Health Organization, 1997. (Background document prepared for the regional meeting on decentralization in the context of health sector reform in Africa.)

17 McIntyre D, Klugman B. The human face of decentralisation and integraMcIntyre D, Klugman B. The human face of decentralisation and integra-
tion of health services: experience from South Africa. Reprod Health Mat tion of health services: expe
ters 2003;11(21):108-19.

18 Walker L, Gilson L. We are bitter but we are satisfied: nurses as street level bureaucrats in South Africa. Soc Sci Med 2004;59:1251-61.

19 Gilson L, Palmer N, Schneider H. Trust and health worker performance: exploring a conceptual framework using South African evidence. Soc Sci Med 2005;61:1418-29.

20 Burnham G, Pariyo G, Galiwango E, Wabwire-Mangen F. Discontinuation of cost sharing in Uganda. Bull World Health Org 2004;82:187-95.

21 Joint Learning Initiative. Human resource for health: overcoming the crisis. Boston: Global Health Equity Initiative, 2004.

\title{
System and market failures: the unavailability of magnesium sulphate for the treatment of eclampsia and pre-eclampsia in Mozambique and Zimbabwe
}

\author{
E Sevene, S Lewin, A Mariano, G Woelk, A D Oxman, S Matinhure, J Cliff, B Fernandes, K Daniels
}

Low cost and effective drugs, such as magnesium sulphate, need to be included in initiatives to improve access to essential medicines in Africa

Ensuring the availability of effective drugs for priority health problems remains a key public health issue in many African countries. ${ }^{1}$ Market deficiencies in ensuring drug development for "neglected" diseases affecting developing countries are well described, ${ }^{23 \mathrm{w} 1}$ and several global initiatives are attempting to tackle this. ${ }^{4}$ 2 $2 v e n$ when low cost, effective treatments exist, however, drug availability for many common health problems remains poor in many settings, limiting progress towards achieving the millennium development goals.

One such health problem is the management of pre-eclampsia and eclampsia, important causes of maternal and infant morbidity and mortality. Over
63000 women die annually after eclamptic convulsions, with $99 \%$ of these deaths occurring in low and middle income countries. ${ }^{67 \mathrm{w} 3}$

Evidence is strong for the effectiveness of magnesium sulphate in treating and preventing eclampsia. $^{8-10}$ w4 w5 Magnesium sulphate costs $\$ 0.35$ (£0.19; €0.29) per ampoule ( $40 \mathrm{ml}$ of $10 \%$ magnesium sulphate; Central Medical Stores, Mozambique, April 2005) and has appeared on the World Health Organization's essential medicines list since $1996 .{ }^{11}$ It is of great concern that this effective and low cost drug is

Details of drug regulation, web references w1-w9, and Table 2 are on bmj.com
Department of
Pharmacology, Faculty of Medicine, Eduardo Mondline, University, Mozambique E Sevene pharmacologist A Mariano pharmacologist $\mathrm{J}$ Cliff professor continued over 